caught young and the parents are willing and intelligent people, the process of following the case through to the end of school life involves years. In the case of Lanarkshire children under my care a sufficient length of time has not yet elapsed for the statistical record of children treated and followed through to be of much value. Further, owing to the present voluntary nature of the scheme very many cases have only been examined late in school life and have escaped from observation after the first or second attendance. We have as yet no special myopia schools in the County of Lanark apart from Glasgow. It is to be hoped that these will come later on when the new education authority gets fairly to work.

\title{
NOTES ON A CASE OF ANOMALOUS INNERVATION OF THE LEVATOR PALPEBRAE SUPERIORIS (LEFT)
}

\author{
H. Somerville Martyn, M.A., M.B., Surgeon-Lieut. R.N., \\ ASST. GLASGOW EYE INFIRMARY.
}

A. E. C., aged 44, A.B., admitted to P.H. in June, 1918, was found on examination of his extrinsic muscles, to present the following abnormality, viz., that on looking down and to the right the left levator palpebrae superioris was thrown into action as represented in Fig. 1.

The extraordinary aspect called for verification by repeated tests, and on every occasion the same appearance presented when looking in the direction stated. More detailed examination revealed, further, that on extreme rotation to the right, on a level with the eyes, the left levator came into action and increasingly so, as the eyes were rotated to the right. This is represented in Fig. 2.

The position of the left upper lid was then more minutely investigated when the eyes were turned in the directions mentioned below, with the following results :

\section{Direction of Eyes.}

1. To the right and up.

Up. 2. Straight up.

3. Up and to the left.

4. To the right.

Level. 5. Straight ahead.

6. To the left.

7. On convergence.
Position of Left Upper Lid.

Similar to the right.

Similar to the right,

Similar to the right.

Distinctly elevated

Similar to the right.

Slightly lower than right.

Similar to the right. 


\section{A Case of Anomalous InNervation}

8. Straight down.

Down. 9. Down and to right. 10. Down and to the left.
Slightly higher than right.

Markedly elevated.

No marked difference from right.

I regret that, through oversight, there is no indication of the exact position, on minute examination, of the left upper lid as compared

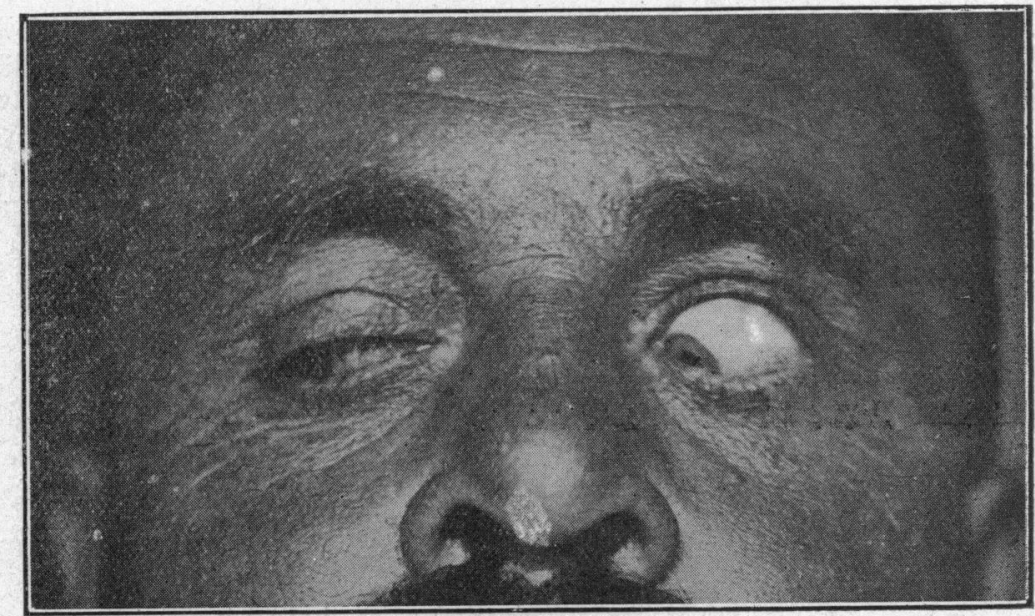

Fig. 1. Test No. 9.

Looking down and to the right.

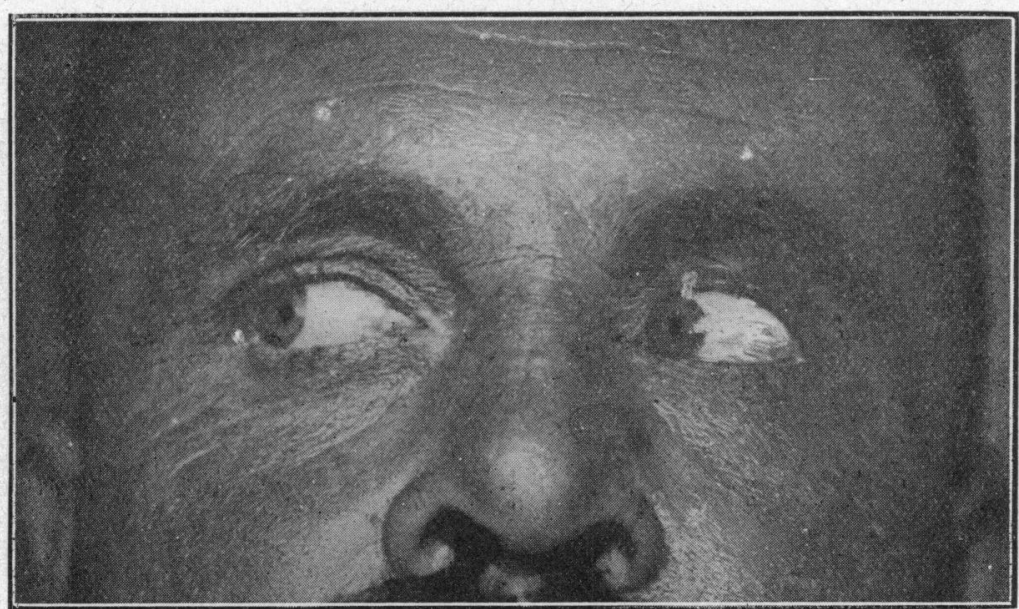

Fig. 2. Test No. 4.

To the right on a level with his own eyes.

. 
with the right, when the gaze was directed down and to the left. Tests frequently repeated when the abnormality was first observed, however, render it certain there was no marked difference from the right.

Visual acuity unaided R. and L. each 6/24. With correction ' R.V. 6/9 partly, L.V. 6/9.

Diplopia none and no evidence of strabismus. One candle only seen when patient tested in dark room with a pair of red and green spectacles.

Some esophoria was present, the distance between the spot and the line of light with the Maddox rod at a distance of nine feet varying from five to eight inches. The discs were congested and their margins not well difterentiated from the surrounding fundus. The fields were slightly contracted on the temporal sides. Syphilis in 1895 , but the anomaly of extrinsic muscles was remarked upon by his family, prior to that date.

The difference in width between the right and the left interpalpebral spaces was most marked in test No. 9 (Fig. 1). Very much less marked in test No. 4 (Fig. 2), and the difference between the right and left spaces in tests 6 and 8, whilst distinct, was very slight in degree, and was only discerned after minute inspection. Photographs would have been of very doubtful value in these cases.

$\checkmark$ On July 16 , I find this note confirming previous examination: "There can be no doubt whatever, that on rotation of his eyes to the right on a level with his own eyes, the left levator palpebrae superioris comes into action distinctly and the interpalpebral space in the left eye is considerably greater than in the right. If the object fixed by the patient be now lowered to a position down and to the right, the difference in width between the right and the left interpalpebral spaces becomes much more accentuated, but this seems entirely due to the drooping of the right upper lid rather than to any further elevation of the left."

Fig. No. 2 seems less marked than the actual, but even as it is measurement as between the right and the left interpalpebral spaces is conclusive as is also the manner in which the tarsal border of the left upper lid is tucked up under the fold of skin above, as compared with the right. As to aetiology, I was at first disposed to regard the case as one of anomalous innervation of the levator palpebrae from the fourth nerve as additional to the usual innervation, elevation occurring when the 1 . sup. oblique came into action, but the emphatic statement quoted above on July 16 leaves me less assured. The constant elevation of the left lid whenever the left internal rectus comes into play strongly suggests anomalous innervation from that branch of the inferior division of the third nerve 
supplying the internal rectus. This, however, seems less likely anatomically.

The case was first discovered in the course of routine examination of extrinsic muscles in the eight cardinal directions, and the extraordinary appearance of the patient on looking down and to the right at once arrested attention (Fig. 1).

It is perhaps not surprising that the facts relative to Fig. 2 were only discovered on minute investigation. At first routine examination the elevation was overlooked.

Publication is possible only with permission of the Medical Director General of the Navy, whose kindness is herewith gratefully acknowledged.

\section{ARTIFICIALLY PRODUCED OPHTHALMIA}

BY

G. McPherson,

LIEUT.-COL. I.M.S., CONSULTING OPHTHALMIC SURGEON, M.E.F.
P. G. DOYNe,

CAPT., R.A.M.C. OPHTHALMIC SPECIALIST.

This is a condition commonly found amongst Indian troops and followers in the Mesopotamian Expeditionary Force. During the year 1917-18 there were 136 cases recorded, whilst during the same period amongst Indians there were 500 cases of conjunctivitis and 554 of trachoma. The substances mostly used for its production are jequirity, croton oil, and castor oil seeds. On searching the patient's kit we have found all these varieties of seeds, but most frequently jequirity. Most medical men are acquainted with the appearance of castor oil and croton oil seeds, but many, unless they have resided in the East, may not be familiar with jequirity. It is a red seed about the size of a small pea with a little black spot on it and is used by Indian jewellers as a weight. All the abovementioned seeds can be easily procured in the bazaar. A small . piece of the pulp which is white is used, and if found in the eye might be mistaken for a piece of inspissated mucus.

The irritant as a rule is introduced into the lower fornix as this is more accessible, but occasionally it may be introduced into the upper fornix as well and very rarely into upper fornix alone. When introduced into the lower fornix a severe inflammation of the lower lid and lower part of the eyeball results. There is a marked swelling of the mucous membrane of the lower lid, often with oedema of the skin. There is intense chemosis of the fornix and lower half of the bulbar conjunctiva, with usually some ecchymosis at the centre of the lower fornix. This ecchymosis is no doubt due to the fact that the irritant has rested on that spot and consequently 